\title{
Development and validation of a questionnaire for teacher effective communication in Qur'an learning
}

\begin{abstract}
A student's perception of teacher effective communication influences the learning atmosphere. The measurement of perception indicates how students view the quality of learning. As few studies have explored the development of an appropriate measurement tool of students' perception of learning to read the Qur'an, this study aims to develop such a tool. Conceptual analysis and a survey using open-ended questions resulted in dimensions and items. Six experts and three instructors evaluated the content validity. The questionnaire was then administered to 421 participants - 201 for Exploratory Factor Analysis (EFA) and 220 for Confirmatory Factor Analysis (CFA). The results successfully identified four dimensions that explained $64.6 \%$ of the variation. The instrument consisted of 13 items with satisfactory reliability and validity. The dimension with the highest coefficient path was 'understanding and friendliness' (UF), while the dimension of 'learning media' (LM) was the lowest. There was a significant influence of gender on the dimension of UF, as well as verbal (V) and non-verbal (NV) communication, while there were no differences in the dimension of LM. The questionnaire can be effectively used as a measurement device of dimensions related to students' perception of teacher effective communication in Qur'an learning.
\end{abstract}

Keyword: Student perception; Teacher communication; Qur'an teaching; Islamic education 